\title{
COMPREENSÃO SOBRE O ATENDIMENTO HUMANIZADO EM UM AMBULATÓRIO DE ODONTOLOGIA DA MARINHA
}

\section{Understanding humanized care at a Navy outpatient Dental Clinic \\ Conocimiento de la atención humanizada de un ambulatorio de odontología de la Marina}

\author{
Klaus Almeida do Rosário Silva iD \\ Universidade de Fortaleza - UNIFOR - Fortaleza (CE) - Brasil
}

Aldo Angelim Dias (iD

Universidade de Fortaleza - UNIFOR - Fortaleza (CE) - Brasil

\section{RESUMO}

Objetivo: Compreender as diretrizes de ambiência e acolhimento da Política Nacional de Humanização sob a ótica dos cirurgiões-dentistas e usuários de um atendimento ambulatorial odontológico. Métodos: Estudo de abordagem qualitativa, conduzido de dezembro de 2017 a fevereiro de 2018, realizado na Escola de Aprendizes-Marinheiros do Ceará (EAMCE), em Fortaleza, Brasil. Os dados foram obtidos em entrevistas semiestruturadas, com cinco cirurgiões-dentistas e onze usuários do ambulatório de odontologia, por meio da técnica de análise de conteúdo para tratamento das entrevistas, emergindo, assim, duas categorias temáticas: Percepção dos profissionais: humanização, ambiência e acolhimento; Percepção dos usuários: humanização, ambiência e acolhimento. Resultados: Os cirurgiões-dentistas reconheceram a importância da associação da ambiência à tranquilidade e confiança e o acolhimento à escuta cuidadosa dos pacientes. Os usuários consideraram a ambiência satisfatória, articulando acolhimento à confiança. Poucas ressalvas, de ambas as partes, indicaram algum comprometimento das práticas de humanização, mau aproveitamento do espaço da sala de espera e demora no agendamento dos atendimentos. Conclusão: Há consenso entre os entrevistados sobre a satisfação com a ambiência e acolhimento no ambulatório, contudo, com algum comprometimento, devido à priorização de funções específicas do militarismo, tais como: serviços de segurança e formaturas militares.

Descritores: Humanização da Assistência; Acolhimento; Odontologia.

\section{ABSTRACT}

Objective: To understand the guidelines on ambience and user embracement within the National Humanization Policy from the perspective of dental surgeons and users of a dental outpatient clinic. Methods: A qualitative study was carried out from December 2017 to February 2018 at the Ceará Navy Academy (Escola de Aprendizes-Marinheiros do Ceará - EAMCE) located in Fortaleza, Brazil. Data were collected by conducting semi-structured interviews with five dental surgeons and eleven users of the outpatient dental clinic and the interviews were treated using the content analysis technique. Two thematic categories emerged: Professionals' perception: humanization, ambience and user embracement; Users' perception: humanization, ambience and user embracement. Results: The dental surgeons recognized the importance of the association of ambience with tranquility and trust and of user embracement with carefully listening to patients. The users rated ambience as satisfactory and associated user embracement with trust. Both professionals and users reported a few obstacles to humanization practices, such as the poor use of the waiting room and the delay in scheduling appointments. Conclusion: There was consensus among the interviewees (professionals and clients) about their satisfaction with the ambience and user embracement at the outpatient clinic; however, humanization may be hindered by the prioritization of military activities, such as security services and military graduations.

Descriptors: Humanization of Assistance; User Embracement; Dentistry.

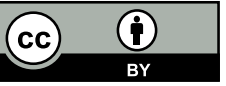




\section{RESUMEN}

Objetivo: Conocer las directrices del ambiente y acogida de la Política Nacional de Humanización desde la perspectiva de los cirujanos-odontólogos y los usuarios de un ambulatorio de odontología. Métodos: Estudio de abordaje cualitativo realizado entre diciembre de 2017 y febrero de 2018 en la Escuela de Aprendices-marineros de Ceará (EAMCE) de Fortaleza, Brasil. Se recogieron los datos de las entrevistas semiestructuradas de cinco cirujanos-odontólogos y once usuarios del ambulatorio de odontología a través del análisis de contenido para el tratamiento de las entrevistas de las cuales han emergido dos categorías temáticas: Percepción de los profesionales: humanización, ambiente y acogida; Percepción de los usuarios: humanización, ambiente y acogida. Resultados: Los cirujanos-odontólogos reconocieron la importancia de la asociación entre el ambiente y la tranquilidad y la confianza y la acogida de la escucha cuidadosa de los pacientes. Los usuarios consideran el ambiente satisfactorio articulando la acogida con la confianza. Las pocas críticas de ambas partes indicaron algún comprometimiento de las prácticas de humanización, el mal aprovechamiento del espacio de la sala de espera y el retraso para el señalamiento de las consultas. Conclusión: Hay un consenso entre los entrevistados (profesionales, clientes) sobre la satisfacción con el ambiente y la acogida del ambulatorio, sin embargo, con algún comprometimiento debido la prioridad de las funciones específicas del militarismo tales como los servicios de seguridad y las formaciones militares.

Descriptores: Humanización de la Atención; Acogimiento; Odontología.

\section{INTRODUÇÃO}

Diante dos vários desafios de tornar o Sistema Único de Saúde (SUS) um sistema que trate seus usuários como cidadãos de direito, após vários debates acerca da humanização e do acolhimento no atendimento em saúde, foi criada pelo Ministério da Saúde, em 2003, a Política Nacional de Humanização (PNH) ou HumanizaSUS, consolidando os programas existentes, porém de forma fragmentada, baseada nos princípios da humanização, tais como o Programa de Atenção ao Parto e Pré-Natal, e o Programa Nacional de Humanização da Assistência Hospitalar. A PNH, que tem como registro oficial o seu Documento Base, apresenta como objetivo fortalecer o SUS, enquanto política pública de saúde, através da promoção de relações de trabalho que valorizem os agentes do SUS e seus usuários ${ }^{(1,2)}$.

A PNH estimula a interação entre gestores, trabalhadores e usuários por meio da comunicação, com o intuito de construir processos coletivos para combater as relações de poder, trabalho e afeto que acabam, muitas vezes, gerando atitudes desumanizadoras, prejudicando a autonomia e a corresponsabilidade dos profissionais de saúde e o cuidado do usuário sobre si mesmo ${ }^{(1)}$. Ao beneficiar a autonomia e o protagonismo dos usuários, bem como favorecer a troca de saberes técnicos e populares (superando as relações de poder), a humanização constitui-se em um potencial instrumento para a promoção em saúde, impactando na qualidade de vida.

A PNH apresenta como uma das suas diretrizes o acolhimento, definindo-o como o reconhecimento da demanda do outro como legítima e singular necessidade. O acolhimento pressupõe a recepção, a escuta, a orientação, o atendimento e o encaminhamento atenciosos das demandas de saúde ${ }^{(1)}$. Significa, ainda, o acompanhamento cuidadoso e respeitoso dessas necessidades até sua resolução( ${ }^{(3)}$.

A ambiência se apresenta como outra diretriz da PNH, baseada na criação de um espaço acolhedor e confortável, com capacidade de transformar os processos de trabalho. A ambiência denota, também, o tratamento do espaço físico, que faz parte do recinto social onde as relações interpessoais entre profissionais e usuários acontecem, devendo ser um lugar acolhedor e resolutivo, contribuindo para um atendimento humanizado na produção de saúde ${ }^{(1)}$.

A humanização no atendimento é um princípio previsto não somente na Política Nacional de Humanização, mas também é um valor fundante da Política Nacional de Promoção da Saúde (PNPS) ${ }^{(4)}$. Nesse sentido, as duas políticas de Estado apresentam modelos de atenção e gestão que convergem para a humanização como eixo comum, seja no respeito e acolhimento das demandas dos seus atores, seja nas práticas coletivas de cuidados humanizados para produção de promoção da saúde.

O interesse por esse objeto de estudo deve-se a uma aparente contradição ao se fazer uma reflexão sobre a Política Nacional de Humanização no campo de atuação militar, surgindo um questionamento sobre como se estabelecem as diretrizes de acolhimento e ambiência no atendimento odontológico, entre usuários e profissionais de saúde, nesse campo peculiar. As práticas humanizadas preconizadas podem levar ao pensamento de que há uma incompatibilidade perante a formação hierarquizada e a rigidez disciplinar de uma instituição militar.

Assim, este estudo propôs uma compreensão(5) de que categorias aparentemente contraditórias possam não ser autoexcludentes, podendo coexistir de uma forma adaptada e singular. Justifica-se pelo retorno que seus 
resultados poderão proporcionar, como o aprimoramento aos processos humanizados de saúde no campo de trabalho militar, dando visibilidade às necessidades e subjetividades dos usuários e profissionais de saúde, bem como pela contribuição acadêmica que o estudo poderá elucidar nos questionamentos suscitados pelos autores. Diante desse contexto, traçam-se os seguintes pressupostos do estudo: Como será que os cirurgiões-dentistas percebem a humanização, as diretrizes de ambiência e o acolhimento, presente na Política Nacional de Humanização, ao atenderem seus pacientes no ambiente militar? Por sua vez, qual a percepção dos usuários sobre a humanização, as diretrizes de ambiência e acolhimento, presente na Política Nacional de Humanização ao serem atendidos pelos Cirurgiões-Dentistas?

Para efeito do objetivo deste estudo, buscaram-se compreender as diretrizes de ambiência e acolhimento da Política Nacional de Humanização sob a ótica dos cirurgiões-dentistas e usuários de um atendimento ambulatorial odontológico.

\section{MÉTODOS}

Pesquisa de abordagem qualitativa(5), adequando-se a esse estudo por ser capaz de incorporar significados, motivos, aspirações, crenças, valores e atitudes, o que corresponde a um espaço mais profundo e subjetivo das relações, dos processos e dos fenômenos, os quais não podem ser reduzidos à operacionalização de variáveis.

O lócus do estudo deu-se na Escola de Aprendizes-Marinheiros do Ceará (EAMCE); uma instituição de formação de pessoal para a Marinha do Brasil com sede na cidade de Fortaleza, Ceará, Brasil. Trata-se de uma unidade militar voltada para o ensino, contudo oferece atendimento ambulatorial de saúde, compondo a rede do Sistema de Saúde da Marinha (SSM), direcionada ao atendimento dos seus usuários, que compreendem militares, seus dependentes e pensionistas. No Brasil, os beneficiários do SSM totalizam mais de 343 mil usuários, sendo que, somente no estado do Ceará, a demanda potencial é de mais de 6.503 usuários ${ }^{(6)}$.

O funcionamento da Marinha do Brasil envolve uma estrutura de condutas fortemente pautada sobre os pilares da hierarquia e disciplina, direcionados para a defesa das ordens interna e externa. Tais pilares, sobretudo a hierarquia, são parâmetros que formatam as relações interpessoais segundo uma lógica própria de escalonamento do poder, informando a antiguidade de cada membro, inclusive dos cirurgiões-dentistas militares, constituindo não somente sua posição social na instituição, mas o comportamento dele esperado ${ }^{(7)}$. Conforme exposto nos resultados deste estudo, tal formatação das relações interpessoais confere um diferencial que impacta o processo de produção de saúde entre o cirurgião-dentista (CD) militar e o usuário militar.

O ambulatório odontológico da Escola de Aprendizes-Marinheiros do Ceará, segundo relato do seu oficial encarregado, presta atendimento diário, com cinco profissionais oficiais $C D$ que fazem parte do quadro temporário da Marinha do Brasil (MB), com capacidade para atender seis pacientes por dia, para cada CD, totalizando 30 atendimentos diários, com uma jornada de trabalho de 40 horas semanais. Oferece as seguintes especialidades: Prótese (atendimento básico), Cirurgia (básica e de terceiros molares), Odontopediatria, Dentística e Endodontia. $O$ funcionamento na instituição é realizado de segunda a sexta-feira, das $8 \mathrm{~h}$ às $16 \mathrm{~h}$, contudo o setor de Odontologia, onde foi realizada a pesquisa, funciona em regime de turnos, das $7 \mathrm{~h}$ às $19 \mathrm{~h}$. Juntamente com a Odontologia, funcionam, no setor da saúde, o atendimento médico ambulatorial, a Junta Regional de Saúde, o laboratório de análises clínicas e o Serviço Social. A recepção é única para o acolhimento inicial e agendamento de todos os setores. No dia da consulta, o usuário aguarda o atendimento na sala de espera do andar superior, dividida com os setores de Serviço Social e Junta Regional de Saúde.

Fizeram parte do estudo os usuários do serviço e os cirurgiões-dentistas que prestavam atendimento no local no período de coleta de dados. Procedeu-se a visitas ao local do serviço, momento em que os participantes foram convidados a compartilhar do estudo, após conhecimento dos objetivos. Assim, os usuários deveriam ser beneficiários do Sistema de Saúde da Marinha (SSM) na região do Ceará e serem maiores de 18 anos. Por parte dos cirurgiões-dentistas, houve participação de todos os cinco profissionais que trabalhavam nessa unidade, nenhum se negou a participar. Por parte dos usuários, entrevistaram-se onze beneficiários, observando-se, para encerramento da amostra, a saturação das respostas da pesquisa, ou seja, um quantitativo satisfatório para demonstração da complexidade das relações envolvidas no processo de produção da saúde, de modo que novas coletas de dados não Ihe acrescentariam descobertas ${ }^{(8)}$.

A coleta de dados ocorreu no período de dezembro de 2017 a fevereiro de 2018, após o término do atendimento. Utilizou-se a técnica de entrevistas semiestruturadas, sendo considerado um instrumento adequado de coleta de dados para esse tipo de pesquisa qualitativa, pois possui um roteiro flexível, com perguntas abertas, respeitando a liberdade do entrevistado para a construção da narrativa ${ }^{(5)}$. Teve-se o cuidado de providenciar um local privativo, 
respeitando-se o tempo mínimo de 20 minutos para cada entrevista. Estabeleceu-se uma relação entrevistador/ entrevistados predominantemente colaborativa, ocorrendo episódios de curiosidade sobre o tema e de entusiasmo pela oportunidade de opinar.

As respostas foram gravadas para posterior análise, sendo aplicados instrumentos com dois tipos de perguntas: um direcionado para os usuários, outro para os $C D$. A primeira parte foi relacionada à profissão e sexo, além da identificação do vínculo do entrevistado com a MB. A segunda parte continha uma pergunta sobre a percepção de cirurgiões-dentistas e dos usuários sobre ao humanização, acolhimento e a ambiência no atendimento odontológico.

O tratamento do material obtido nas entrevistas obedeceu ao procedimento para Análise de Conteúdos ${ }^{(5)} \mathrm{em}$ pesquisa qualitativa, que possui três fases: préanálise, exploração do material, e o tratamento dos resultados alcançados e interpretação. A primeira fase, pré-análise, é alcançada para sistematizar os conceitos iniciais postos pelo quadro referencial teórico e compor apontadores para a explicação dos elementos coletados. A segunda fase, a exploração do material, acontece na constituição das operações de codificação, contemplando os recortes dos textos em unidades de registros, a definição de regras de apuração e a disposição e associação dos dados em categorias simbólicas ou temáticas. A terceira fase abrange o tratamento dos resultados e a interpretação, visando apreender os conteúdos evidentes e ocultos contidos em todo o material coletado (entrevistas, documentos e observação). Ressaltando os aspectos tidos como análogos e os estimados diferentes; assim, da análise temática, emergiram duas categorias, a citar: Percepção dos profissionais: humanização, ambiência e acolhimento; Percepção dos usuários: humanização, ambiência e acolhimento.

A pesquisa recebeu aprovação do Comitê de Ética da Universidade de Fortaleza - UNIFOR sob Parecer $n .^{\circ}$ 2.080.439. O estudo atendeu ao recomendado na Resolução n. ${ }^{\circ} 466 / 12$ do Conselho Nacional de Saúde ${ }^{(9)}$ sobre pesquisas envolvendo seres humanos. Os participantes assinaram o Termo de Consentimento Livre e Esclarecido/ TCLE. Para manter o anonimato, foram identificados como "Usuário (U) 1 a 11" e, para os cirurgiões-dentistas (CD), identificados como "CD 1 a 5 ".

\section{RESULTADOS E DISCUSSÃO}

Neste espaço serão apresentados os resultados do estudo no que diz respeito aos dados relacionados aos entrevistados, logo após se apresentam as categorias que emergiram do estudo, discutindo-as a partir dos trechos de falas do texto original e articulando-as teoricamente.

\section{Dados relacionados aos entrevistados}

Os cirurgiões-dentistas entrevistados pertencem ao quadro de oficiais temporários da ativa, sendo três do sexo feminino e dois do sexo masculino. Já entre os entrevistados, onze ao todo, havia: três sargentos da ativa, três sargentos inativos, um suboficial da ativa, um inativo, um marinheiro da ativa, um inativo e apenas uma entrevistada era oficial da ativa; sendo dez usuários do sexo masculino e uma do sexo feminino.

\section{Percepção dos profissionais: humanização, ambiência e acolhimento}

Esta categoria trata da percepção dos profissionais sobre a humanização, ambiência e acolhimento no atendimento. Sabe-se que a humanização pode ser entendida como a criação e desenvolvimento de vínculos entre profissionais e usuários, fundamentadas em ações direcionadas pela percepção e valorização dos sujeitos, refletindo atitudes éticas e humanas ${ }^{(10,11)}$. Quanto à percepção dos profissionais CD entrevistados sobre humanização, pôde-se apreender:

"[...] é conversar e contar a vida [...] saber um pouco sobre a vida daquele paciente, [...] a melhor forma de fazer a intervenção necessária." (CD 2)

"[...] O paciente é sempre ouvido, e tratado da melhor maneira possível [...]." (CD 3)

As respostas indicaram uma compreensão de que a humanização no atendimento odontológico da instituição ocorre através da comunicação, de diálogos e de escutas qualificadas entre usuário e profissional. Os entrevistados demonstraram também um posicionamento respeitoso no atendimento e uma escuta atenta dos pacientes.

Também houve aparente contradição em relação à associação direta entre humanização, hierarquia e disciplina. As exceções se relacionaram com o acúmulo de encargos colaterais, inerentes ao ambiente militar:

"[..] é, aqui na Marinha, devido a gente ter uma disciplina e hierarquia, a gente já tem uma humanização bem, bem bacana. " (CD1) 
"[...] no meio entre os militares (na corporação) é que não existe humanização, pelo contrário. O meio militar, ele está para atividades que não sejam o atendimento ao público [...], já para o público é humanizado... sim." (CD2)

Segundo $0 ~ § 1^{\circ}$ do art.14 do Estatuto dos Militares ${ }^{(12), ~ " a ~ h i e r a r q u i a ~ m i l i t a r ~ e ́ ~ a ~ o r d e n a c ̧ a ̃ o ~ d a ~ a u t o r i d a d e, ~ e m ~ n i ́ v e i s ~}$ diferentes (...). O respeito à hierarquia é consubstanciado no espírito de acatamento à sequência de autoridade". A disciplina é definida no $\S 2^{\circ}$ do mesmo artigo como "a rigorosa observância e o acatamento integral das leis, regulamentos, normas e disposições (...), traduzindo-se pelo perfeito cumprimento do dever por parte de todos e de cada um dos componentes desse organismo." Portanto, a hierarquia está baseada no escalonamento da autoridade e a disciplina, na rigorosa obediência às ordens, ambas supondo uma ideia de dureza e severidade, que não costumam ser automaticamente associadas à humanização, como contraditoriamente sugere o depoimento acima (CD1).

A respeito dessa contraposição, uma pesquisa realizada nas áreas de psicologia militar, administração e direito militar obteve resultados que distanciam o campo militar da humanização, sobretudo no que se refere à diretriz de acolhimento e ao quesito respeito. Tais resultados indicaram elevada ansiedade entre os militares devido à pressão organizacional pela perfeição, eficiência e rapidez baseadas no excesso de cobranças disciplinar ${ }^{(13)}$; comprometimento da qualidade de vida no trabalho, ocasionado por desrespeito dos superiores aos subordinados e pelo excesso de regras $^{(14)}$; e sofrimento moral gerado por ameaças recorrentes de tipificação criminal da indisciplina (descumprimento de ordens) por parte de alguns superiores que pressupõem a hierarquia como um poder absoluto(15).

As falas dos entrevistados CD1 e CD2 mencionaram uma humanização possível no atendimento ao público em geral, contudo separada das atividades militares propriamente ditas. O que pode significar que a humanização só seria exequível no ambiente militar desde que separada e isolada das características mais marcantes das atividades militares, tornando-se possível em situações em que o comando e o cumprimento de ordens não precisem ser tão rigorosos e radicais, tal como no atendimento ao usuário. O que traz uma singularidade às práticas de humanização no ambiente militar, neste caso, ocupa um lugar delimitado, pois são inseridas no espaço entre o atendimento ao público e as tarefas de treinamento para o combate.

Outros fatores que, para os CD entrevistados, podem comprometer o atendimento humanizado seriam os encargos colaterais e demais atividades próprias do cotidiano militar. Segundo o art. 6-4-16 da Ordenança Geral para o Serviço da Armada (OGSA) ${ }^{(16)}$, encargo colateral "é aquele exercido por Oficial cumulativamente com qualquer cargo para o qual haja sido designado". Assim, trata-se das obrigações extra-atendimento odontológico, como formaturas militares, desfiles e serviço de segurança da unidade:

"[...] um dentista de serviço, o serviço armado da Escola (...). Então para um serviço mais humanizado, eu acredito que precisaria [...] full time dentro da Odontologia, mas... nós sabemos que é função nossa. Antes de sermos dentistas, somos militares [...]." (CD3)

"[...] o militarismo é muito cobrado [...] é constante essa luta para a gente priorizar o atendimento, [...] o paciente [...] acaba ficando em segundo plano e [...] reclamando um pouco disso." (CD4)

Os encargos colaterais e demais atividades militares podem representar um conflito, prejudicando a humanização em virtude da falta de tempo para o atendimento e da obrigação de cumprir outras atividades. Ao mencionar que o paciente, às vezes, fica em segundo plano, porque o militarismo é muito cobrado, o profissional expõe a relevância da hierarquia sobre o atendimento odontológico em si (CD1), confrontando-se com algumas diretrizes da PNH. Neste caso, isto gera uma demora no atendimento e um aumento da fila de espera, impactando diretamente sobre a qualidade do acolhimento e da humanização.

Uma educação permanente abrange todos os atores envolvidos no processo de humanização em saúde ${ }^{(17,18)}$. Ela é capaz de solucionar problemas que podem contribuir no processo de humanização em saúde, pois pode proporcionar conhecimentos atualizados sobre o assunto, além de renovar o compromisso dos atores envolvidos com a importância do atendimento humanizado. Essa também foi a conclusão a que chegou um estudo sobre os modelos e instrumentos de humanização adotados em diversos países, como Brasil, Estados Unidos, Itália e França, revelando que, nesses países, a falta de protagonismo da humanização na formação acadêmica é um importante obstáculo para a abordagem centrada no paciente ${ }^{(19)}$.

Como a ambiência é o local onde ocorre o contato do usuário com o serviço prestado, onde serão registradas as primeiras impressões, deve ser apresentada com impressão positiva, estimulando a segurança e a confiança do usuário no decorrer do atendimento. Além da importância da estrutura física do local, que contribui para a qualidade do serviço oferecido, a ambiência é considerada uma qualidade de ambiente de cura. O paciente aumenta sua percepção positiva através dos componentes físicos e não físicos presentes nele, promovendo uma expectativa favorável acerca dos procedimentos a serem realizados ${ }^{(10,20)}$. Já o acolhimento acontece através de uma escuta de 
boa qualidade, ofertada pelos trabalhadores às demandas do usuário, oportunizando o acesso deles a tecnologias apropriadas às suas necessidades, aumentando a efetividade das práticas de saúde ${ }^{(1)}$.

Estudos indicam, segundo os entrevistados, que o atendimento odontológico envolve procedimentos geradores de ansiedade e de estresse em virtude da possível invasão de parte do corpo físico, levando-os à percepção da situação como ameaçadora ${ }^{(21,22)}$. Corroborando essa percepção, os CD entrevistados no presente estudo também mencionaram sentimentos de medo e de ansiedade presentes no atendimento odontológico e também que a observância da ambiência poderia ser algo que amenizasse esses sentimentos no usuário:

"[...] a questão do local de atendimento, da recepção em si, [...] isso tudo influencia para que o paciente fique mais calmo, ele fique menos apreensivo [...]." (CD1)

"[..] ambiência, [...] é importante porque o paciente vai entrar mais tranquilo na sala. [...] um local onde [...] ele vai ter uma revista pra ler. Vai conversar com os outros pacientes [...], tem uma televisão pra ele assistir. [...]." (CD3)

O medo e ansiedade, por vezes, são inerentes aos pacientes submetidos ao tratamento odontológico, mas um fator minimizador desse estresse é a característica acolhedora da ambiência da sala de espera e do consultório, favorecendo maior qualidade e tranquilidade aos atos e modos que constituem os processos de trabalho em saúde(23).

Em relação ao conceito de acolhimento e sua importância para a saúde, os profissionais entrevistados no atual estudo enfatizaram a palavra "confiança" como importante atitude acolhedora, capaz de quebrar paradigmas através da criação de laços e da interação com os usuários, além de valorizar o diálogo, a atenção e o respeito. Tudo isto para que se favoreça um atendimento mais resolutivo e humanizado ${ }^{(1)}$ :

"[...] quebrar aquele paradigma de que o dentista ocasiona dor, então você acolhendo, [...] você consegue a confiança do paciente [...]." (CD 2)

"[...] o acolhimento [...] deve quebrar essa barreira entre o paciente e profissional, para o paciente se sentir à vontade e falar tudo que ele deseja [...]." (CD 4)

\section{Percepção dos usuários: humanização, ambiência e acolhimento}

A categoria trata da percepção dos usuários quanto à humanização, ambiência e ao acolhimento, e permitiu evidenciar que o ambiente da sala de espera foi considerado bom, mas alguns citaram que poderia ser melhorado, como pode ser visto nas falas a seguir:

"O espaço é muito distante e acaba quebrando a boa receptividade que o setor deveria ter, (...) poderia ter um pouco mais de ventilação[...]." (Usuário 9)

"[...] se você não está numa boa sala de espera... você fica tenso [...] não é um ambiente ruim, mas [...] não é o ideal [...] um cafezinho, um jornal." (Usuário 6)

Os usuários entrevistados que se mostraram satisfeitos com a ambiência relataram que as instalações não eram luxuosas, mas consideradas adequadas e suficientes. Alguns fatores, como um espaço muito grande e pouco aproveitado, cadeiras desconfortáveis e ausência de jornais e revistas, podem influenciar negativamente a primeira impressão que o usuário tem sobre o serviço, motivando um possível afastamento e uma desconfiança em relação ao atendimento, assim como aumentar seu nível de ansiedade ${ }^{(23)}$.

Com vistas a melhorar a ambiência da sala e, portanto, o seu acolhimento, poderiam ser tomadas algumas medidas, com o respectivo apoio institucional, para favorecer a hospitalidade, como pintura das paredes em cor menos neutra (atualmente é cinza claro), ornamentação com plantas e quadros e disponibilização de revistas e jornais. Assim, pode-se transformar um espaço físico funcional em um espaço social acolhedor ${ }^{(17)}$.

Os usuários entrevistados consideraram o acolhimento, por vezes, insatisfatório, devido à demora em ser chamado para o atendimento e pela distância física entre as cadeiras da sala de espera e a entrada do setor de Odontologia, o que leva o usuário a ser chamado num tom mais elevado de voz pelos auxiliares, comprometendo tanto a ambiência quanto o acolhimento, diretrizes indissociáveis da $\mathrm{PNH}$. A redução dessa distância poderá representar simbolicamente uma aproximação entre as expectativas e percepções de ambos os lados, contribuindo positivamente para o acolhimento ${ }^{(24)}$. Nesse aspecto, a demora em ser chamado evidenciou um alinhamento das respostas dos usuários com a dos profissionais, reforçando que esse problema é bastante impactante no acolhimento.

Essa convergência de respostas entre os atores envolvidos no processo de saúde indica um aspecto fundamental do comprometimento das práticas de humanização no campo militar, pois revela que o tempo e a necessidade do 
usuário não são respeitados conforme preconizado na $\mathrm{PNH}$, deixando, o atendimento ao usuário, de se constituir em uma prioridade para os profissionais de saúde. Esse aspecto é merecedor de uma mudança na política institucional, que deve estabelecer como prioridade o compromisso com a humanização no processo de produção de saúde ${ }^{(25)}$ :

"[...] a demora, devido ao número de dentistas ser pequeno e [...] dar serviço na Sala de Estado [entrada principal da unidade militar], [...] ter que remarcar a mesma consulta [...] passar meses sem ser atendido [...]." (Usuário 1)

"[...] o espaço é muito distante [...] quebrando a boa receptividade [...] chama-se o paciente da entrada do consultório que é distante [...] ao invés de ser convidado, o nome dele é gritado [...]." (Usuário 9)

Por outro lado, os usuários relataram sentir confiança e elogiaram a competência da equipe de cirurgiõesdentistas, dois fatores muito importantes para a humanização do atendimento, pois a qualidade do relacionamento entre ambos, usualmente é considerada, pelos usuários, tão importante quanto a capacidade técnica do profissional(25):

"[...] confiança por parte dos profissionais [...] a parte profissional tudo ok, muito bom." (Usuário 3)

"[...] pessoal sempre muito atencioso e [...] equipe sempre profissional, sempre prestativa." (Usuário 8)

Essas falas são relevantes, pois é a partir do conhecimento do profissional sobre os sentimentos do usuário que se começa a construir um vínculo de confiança, aliado a uma explicação clara dos procedimentos que serão realizados e à participação do usuário na decisão do plano de tratamento. A confiança do usuário sobre o profissional também é formatada a partir de sua bagagem de vivências e do que ele considera como valores importantes, tais como respeito e transparência ${ }^{(26)}$.

Dessa forma, é construída uma relação acolhedora de confiança que, ao promover o comportamento cooperativo, adequando a ação do profissional às necessidades do usuário, lhe confere um caráter de prática de cuidado humanizada, potencializando os resultados da produção em saúde ${ }^{(27)}$.

Os resultados obtidos ratificam achados presentes na produção acadêmica, tais como: a associação entre ambiência, acolhimento, escuta e respeito na produção de saúde e de subjetividades; a necessidade de educação permanente em humanização e o impacto negativo, sobre a humanização, causado pela demora e dificuldade de acesso aos serviços ${ }^{(28-30)}$. Tais estudos indicam a possibilidade, guardadas as devidas proporções, afetas ao nível de rigor da hierarquia e disciplina, de serem aplicadas aos demais atores envolvidos no processo de saúde em ambulatórios odontológicos, dado que os desafios da implementação de práticas de humanização permeiam o setor da saúde como um todo ${ }^{(30)}$, contribuindo para a Promoção da Saúde da população envolvida.

Acredita-se que este estudo representa um avanço ao dar voz às percepções dos usuários e profissionais de saúde no campo militar. A vocalização das necessidades e subjetividades dos atores implicados no processo de saúde contribui para o alcance dos valores/princípios de participação e da autonomia previstos na PNPS ${ }^{(4)}$, favorecendo a criação de espaços para produção social de saúde e oportunizando a atribuição de importância e significado às ações formuladas e/ou a serem reformuladas ${ }^{(31,32)}$.

Sobre a concepção de novas pesquisas que permitam o aprofundamento do tema, sugerem-se investigações que abordem o impacto das formações profissional e familiar dos trabalhadores de saúde nos resultados das práticas de humanização. Buscar compreender em que medida esses resultados são formatados pelas subjetividades herdadas do repertório trazido do âmbito familiar e/ou pela cultura organizacional na qual estão inseridos, considerando-se que o acolhimento das subjetividades desses atores é uma importante estratégia de ingerência nos processos de saúde.

Sugerem-se, ainda, estudos sobre as práticas de humanização segundo a percepção dos gestores da política de saúde no campo militar, dado que tais atores são responsáveis pela formulação dos ajustes das políticas públicas para sua aplicação nas unidades militares. Sabe-se que o nível de compromisso dos gestores com programas e projetos fundamentados na humanização impacta na interação institucional que, por sua vez, influencia na adesão dos trabalhadores e usuários dessas ações ${ }^{(27,33)}$.

A diversidade contextual desse campo repleto de significados e simbologiastambém impõe seus limites. Portanto, essa análise não esgota todas as versões possíveis da verdade acerca da dinâmica das práticas estudadas, pois os participantes pesquisados são muito mais complexos do que o sugerido e as possibilidades de resposta retratadas sofreram o enquadramento do tempo e do espaço a que pertencem.

\section{CONSIDERAÇÕES FINAIS}

O atendimento no setor de Odontologia foi considerado pelos entrevistados um modelo de humanização específico para a realidade das Forças Armadas. Tal modelo não atendeu plenamente ao ideal proposto na PNH, sobretudo 
no que se refere à diretriz de acolhimento, devido à priorização dos encargos militares que os cirurgiões-dentistas precisam cumprir em detrimento do atendimento clinico. A diretriz de ambiência foi considerada satisfatória pelos atores envolvidos, porém apresentando necessidade de ajustes, como a otimização do uso do amplo espaço físico de espera para torná-lo mais receptivo e favorável ao atendimento humanizado.

Sugere-se que seja uma avaliação sistemática como os usuários aumentando a atenção dispensada, valorizando suas queixas e identificando suas necessidades individuais ou coletivas. Adicionalmente, sugere-se a oferta periódica, aos profissionais e gestores da saúde da unidade militar pesquisada, de cursos de capacitação continuada e de multiplicação em práticas humanizadas de promoção da saúde.

\section{AGRADECIMENTOS E CONFLITOS DE INTERESSE}

Os autores expressam seu sincero agradecimento à Escola de Aprendizes-Marinheiros do Ceará.

Não há conflitos de interesses nesse artigo.

\section{CONTRIBUIÇÕES}

Klaus Almeida do Rosário Silva contribuiu com a concepção, elaboração, análise, interpretação de dados e a redação do manuscrito. Aldo Angelim Dias contribuiu com a orientação metodológica e a revisão do manuscrito.

Manuscrito baseado na monografia: Práticas de Humanização na Odontologia da Marinha em Fortaleza. Universidade de Fortaleza - defesa em 05/06/2018 - 33 páginas.

\section{REFERENNCIAS}

1. Ministério da Saúde (BR). Humaniza SUS: documento base para gestores e trabalhadores do SUS [Internet]. $4^{\mathrm{a}}$ ed. Brasília: Editora do Ministério da Saúde; 2010 [acesso em 2019 Fev 26]. Disponível em: http://bvsms. saude.gov.br/bvs/publicacoes/humanizasus_documento_gestores_trabalhadores_sus.pdf

2. Archanjo JVL, Barros MEB. Política Nacional de Humanização: desafios de se construir uma "política dispositivo". Anais do $15^{\circ}$ Encontro Nacional da Associação Brasileira de Psicologia Social [Internet]. 2009 Out 30 - Nov 02; Maceió, Alagoas. [acesso em 2019 Fev 27]. Disponível em: http://www.abrapso. org.br/siteprincipal/images/Anais_XVENABRAPSO/360.\%20pol\%CDtica\%20nacional\%20de\%20 humaniza\%C7\%C3o.pdf

3. Neves M, Pretto SM, Ely HC. Percepções de usuários e trabalhadores de saúde sobre a implantação do acolhimento em uma Unidade de Saúde em Porto Alegre - RS, Brasil. Rev Odontol UNESP [Internet]. 2013 [acesso em $2017 \mathrm{Fev}$ 02];42(5):364-71. Available from: http://www.scielo.br/pdf/rounesp/v42n5/08.pdf

4. Brasil. Ministério da Saúde. Portaria $n^{\circ} 2.446 / 14$, de 11 de novembro de 2014. Redefine a Política Nacional de Promoção da Saúde [Internet]. 2014 [acesso em 2019 Fev 27]. Disponível em: http://bvsms.saude.gov.br/ bvs/saudelegis/gm/2014/prt2446_11_11_2014.html

5. Minayo M. O desafio do conhecimento: pesquisa qualitativa em saúde. 13ª ed. São Paulo: Hucitec; 2013.

6. Marinha do Brasil. Anuário Estatístico da Marinha. Brasília: SGM; 2015.

7. Leirner PC. A etnografia como extensão da guerra por outros meios: notas sobre a pesquisa com militares. Rev Mana [Internet]. 2009 [acesso em 2018 Fev 28];15(1):59-89. Disponível em: http://www.scielo.br/scielo. php?script=sci_arttext\&pid=S0104-93132009000100003

8. Minayo M. Amostragem e saturação em pesquisa qualitativa: consensos e controvérsias. Rev Pesquisa Qualitativa [Internet]. 2017 [acesso em 2018 Abr 17];5(7):1-15. Disponível em: https://editora.sepq.org.br/ index.php/rpq/article/view/82/59

9. Brasil. Ministério da Saúde. Conselho Nacional de Saúde. Resolução n 466, de 12 de dezembro de 2012: diretrizes e normas regulamentadoras de pesquisas envolvendo seres humanos. Diário Oficial da União; Brasília, 13 Jun 2013. 
10. Rezende MCRA, Lopes MRANE, Gonçalves DA, Zavanelli AC, Fajardo RS. Acolhimento e bem estar no atendimento odontológico humanizado: o papel da empatia. Arch Health Invest [Internet]. 2015 [acesso em 2018 Abr 17];4(3):57-61. Disponível em: http://www.archhealthinvestigation.com.br/ArcHI/article/view/904

11. Azevedo L, Silva E, Félix V, Oliveira R. Humanização no tratamento odontológico. Anais do $1^{\circ}$ Seminário de Humanização HUPAA [Internet]. 2017 Out 26-27. Maceió, Alagoas. [acesso em 2018 Abr 17]. Disponível em: www.seer.ufal.br/index.php/gepnews/article/download/4329/3084

12. Brasil. Lei $n^{\circ} 6.880$, de 09 de dezembro de 1980. Dispõe sobre o Estatuto dos Militares. [Internet]. 1980 [acesso em 2018 Mar 27]. Disponível em: http://www.planalto.gov.br/ccivil_03/Leis/L6880.htm

13. Magalhães J, Silva GA, Santos YR. Os efeitos do stresse e burnout em militares: uma breve revisão bibliográfica para a identificação da problemática. Revista Psique Portugal. [Internet]. 2013 [acesso em 2019 Fev 26];9:75-97. Disponível em: http://repositorio.ual.pt/bitstream/11144/2704/1/Os\%20efeitos\%20do\%20 stresse $\% 20 \mathrm{e} \% 20$ burnout $\% 20 \mathrm{em} \% 20$ militares.pdf

14. Abreu JFS, Adão SARC. A qualidade de vida dos policiais militares [monografia] [Internet]. [Santana do Livramento (RS)]: Universidade Federal do Pampa; 2017. [acesso em 2019 Fev 27]. Disponível em: http:// dspace.unipampa.edu.br/bitstream/riu/2087/1/TCC\%20Jeferson $\% 20-\% 20$ Vers $\%$ C3\%A30\%208\%20 CORRIGIDO.pdf

15. Melo MS. A dissonância do assédio moral em relação aos princípios da hierarquia e da disciplina militares [monografia] [Internet]. [Florianopólis]: Universidade Federal de Santa Catarina; 2016 [acesso em 2019 Fev 27. Disponível em: https://repositorio.ufsc.br/handle/123456789/166242

16. Brasil. Decreto $n^{\circ} 95.480$, de 13 de dezembro de 1987, dá nova redação para a Ordenança Geral para o Serviço da Armada [Internet]. 1987 [acesso em 2018 Mar 27]. Disponível em: https://www2.camara.leg.br/ legin/fed/decret/1980-1987/decreto-95480-13-dezembro-1987-446244-publicacaooriginal-1-pe.html

17. Matos PES, Mendes HJ, Santana ML. Acolhimento aos usuários do serviço de Odontologia de uma universidade pública. Rev ABENO [Internet]. 2016 [acesso em 2018 Abr 18];16(4):85-94. Disponível em: https://revabeno.emnuvens.com.br/revabeno/article/download/304/266

18. Finkler M, Caetano JC, Ramos FRS. Ética e valores na formação profissional em saúde: um estudo de caso. Ciênc Saúde Colet [Internet]. 2013 [acesso em 2018 Fev 18];18(10):3033-42. Disponível em: www.scielo.br/ $\mathrm{pdf} / \mathrm{csc} / \mathrm{v} 18 \mathrm{n} 10 / \mathrm{v} 18 \mathrm{n} 10 \mathrm{a} 28 . \mathrm{pdf}$

19. Tripodi M, Mandato C, Anseris AGE, Siano MA, Quitadano P, Nuzio SG, et al. Humanization of pediatric care in the world: focus and review of existing models and a measurament tools. Rev Ital Pediatr [Internet]. 2017 [acesso em 2019 Fev 16];43:76. Disponível em: https://www.ncbi.nlm.nih.gov/pmc/articles/PMC5577665/

20. Carvalho TV. O acolhimento no ambiente de espera da Odontoclínica Central da Marinha. Arq Bras Med Nav [Internet]. 2011 [acesso em $2017 \mathrm{Fev}$ 02];72(1):35-9. Available from: http://www.redebim.dphdm.mar.mil.br/ vinculos/000002/00000262.pdf

21. Souza RLL, Guimarães ARD, Duarte PCT, Amaral MTR, Costa HS, Silva RLS. Necessidade de tratamento odontológico e níveis de ansiedade em adolescentes. Rev Bahiana de Odontologia [Internet] 2017 [acesso em 2018 Fev 28];8(2):37-42. Disponível em: https://www5.bahiana.edu.br/index.php/odontologia/article/ download/1308/1086. DOI: 10.17267/2238-2720revbahianaodonto.v8i2.1308

22. Rodrigues MP, Costa ICC, Medeiros AR, Souza PHS, Medeiros RM, Carneiro SER, et al. Humanização: fragilidades, desafios e fortalezas em uma escola de odontologia. Rev Espaço para Saúde [Internet]. 2015 [acesso em 2018 Abr 18];16(3):27-38. Disponível em: http://espacoparasaude.fpp.edu.br/index.php/ espacosaude/article/view/393

23. Moreira MADM, Lustosa AM, Dutra F, Barros EO, Batista JBV, Duarte MCS. Políticas públicas de humanização: revisão integrativa de literatura. Ciênc Saúde Colet [Internet]. 2015 [acesso em $2018 \mathrm{Fev}$ 28];20(10):3231-42. Disponível em: http://www.scielo.br/pdf/csc/v20n10/1413-8123-csc-20-10-3231.pdf

24. Neves M, Pretto SM, Ely HC. Percepções de usuários e trabalhadores de saúde sobre a implantação do acolhimento em uma unidade de saúde em Porto Alegre - RS, Brasil. Rev Odontol UNESP [Internet]. 2013 [acesso em 2017 Fev 02];42(5):364-71. Disponível em: http://www.scielo.br/pdf/rounesp/v42n5/08.pdf 
25. Moradi AM, Hosseini SB, Shamloo G. Evaluating the impact of environmental quality indicators on the degree of humanization in healing environments. Space Ontology International Journal [Internet]. 2018 [acesso em 2019 Fev 26];7(1):1-8. Disponível em: http://soij.qiau.ac.ir/ article_540427_42a4b2a0b6e757e566d3d76e44e1fb40.pdf

26. Scherer MDA, Pires DEP, Jean R. A construção da interdisciplinaridade no trabalho da Equipe de Saúde da Família. Ciênc Saúde Colet [Internet]. 2013 [acesso em 2018 Abr 18];18(11):3203-12. Disponível em: http:/l www.scielo.br/scielo.php?pid=S1413-81232013001100011\&script=sci_abstract\&tlng=pt

27. Ministério da Saúde (BR). Secretaria de Atenção à Saúde. Acolhimento na gestão e o trabalho em saúde [Internet]. Brasília: Ministério da Saúde; 2016 [acesso em 2019 Fev 27]. Disponível em: bvsms.saude.gov.br/ bvs/publicacoes/acolhimento_gestao_trabalho_saude.pdf

28. Cotta RM, Reis RS, Campos AAO, Gomes AP, Antonio VE, Siqueira-Batista R. Debates atuais em humanização e saúde: quem somos nós? Ciênc Saúde Colet [Internet]. 2013 [acesso em 2019 Fev 27];18(1):171-9. Disponível em: http://www.scielo.br/scielo.php?pid=S1413-81232013000100018\&script=sci_ abstract\&tlng=es

29. Amorim MCPD. Um modelo de avaliação da Política Nacional de Humanização sob o prisma da eficiência: proposta a partir de estudo de caso no Hospital e Maternidade Dona Íris em Goiânia/GO [Dissertação] [Internet]. [Aparecida de Goiânia (GO)]: Universidade Federal de Goiás; 2018. [acesso em 2019 Fev 26]. Disponível em: https://repositorio.bc.ufg.br/tede/handle/tede/8557

30. Morais TC, Wunsch DS. Os desafios para efetivação da humanização hospitalar: a percepção dos usuários e profissionais de uma unidade de internação pediátrica. Textos Contextos [Internet]. 2013 [acesso em 2019 Mar 25];12(1):100-13. Disponível em: revistaseletronicas.pucrs.br/ojs/index.php/fass/article/ download/13253/9637

31. Mendes R, Fernandez JCA, Sacardo DP. Promoção da saúde e participação: abordagens e indagações. Saúde Debate [Internet]. 2016 [acesso em 2019 Mar 25];40(108):190-203. Disponível em: http://www.scielo. br/scielo.php?pid=S0103-11042016000100190\&script=sci_abstract\&tlng=pt

32. Catanante GV, Hirooka LB, Porto HS, Bava MCGGC. Participação social na atenção primária à saúde: em direção à Agenda 2030. Ciênc Saúde Colet [Internet]. 2017 [acesso em 2019 Mar 25];22(12):3965-74. Disponível em: http://www.scielo.br/scielo.php?pid=S1413-81232017021203965\&script=sci_abstract\&tlng=pt

33. Farias FBB, Vidal LL, Farias RAR, Jesus ACP. Cuidado humanizado em UTI: desafios na visão dos profissionais de saúde. J Res Fundam Care Online [Internet]. 2013 [acesso em 2019 Mar 25];5(4):635-42. Disponível em: https://dialnet.unirioja.es/descarga/articulo/4767896.pdf

Endereço do primeiro autor:

Klaus Almeida do Rosário Silva

Curso de Odontologia da Universidade de Fortaleza - UNIFOR

Av. Washington Soares, 1321

Bairro: Edson Queiroz

CEP: 60811-341 - Fortaleza - CE - Brasil

E-mail: klausalmeida93@gmail.com

\section{Endereço para correspondência}

Aldo Angelim Dias

Universidade de Fortaleza - UNIFOR

Comitê de Ética em Pesquisa e Curso de Odontologia

Av. Washington Soares, 1321

Bairro: Edson Queiroz

CEP: 60811-341 - Fortaleza - CE - Brasil

E-mail: aldo@unifor.br

Como citar: Silva KAR, Dias AA. Humanização em Odontologia na Marinha. Rev Bras Promoç Saúde. 2019;32:8336. 